\title{
A DESERTIFICAÇÃO NO SEMIÁRIDO BAIANO: ANÁLISE DA EVOLUÇÃO DOS INDICADORES SOCIOECONÔMICOS DO PÓLO DE JEREMOABO:
}

\section{Carine Fonseca Menezes Silva ${ }^{1}$; Nacelice Barbosa Freitas ${ }^{2}$;}

1. Bolsista PIBIC/FAPESB, Graduanda em bacharelado em geografia, Universidade Estadual de Feira de Santana, e-mail: carinemeneze@gmail.com

2. Orientador, Departamento de Ciências Humanas e Filosofia, Universidade Estadual de Feira de Santana, e-mail: nacegeografic@ hotmail.com

PALAVRAS-CHAVE: desertificação; semiárido; Pólo de Jeremoabo.

\section{INTRODUÇÃO}

O resumo tem por objetivo explicar a evolução dos números referentes aos indicadores socioeconômicos, no Pólo de Jeremoabo, analisando a relação com o processo desertificação, com o intuito de subsidiar os estudos sobre ordenamento territorial em região de clima semiárido. Nessa perspectiva, tomou-se como referência os indicadores socioeconômicos do Pólo de Jeremoabo, área susceptível à desertificação no domínio de clima semiárido. Buscouse explicar a dinâmica socioeconômica e demográfica dos municípios, especificamente a qualidade de vida com base no Índice de Desenvolvimento Econômico (IDE), Índice de Desenvolvimento Social (IDS) e a Extração Silvícola, tendo como referência os censos demográficos e econômicos do Instituto Brasileiro de Geografia e Estatística (IBGE) no período entre 1998 e 2014, os dados da Superintendência de Estudos Econômicos e Sociais da Bahia (SEI) e informações do Programa das Nações Unidas para o Desenvolvimento (PNUD).

O semiárido brasileiro localiza-se na Região Nordeste ocupando cerca de $19 \%$ do território nacional, e está localizado entre as coordenadas $-46^{\circ} 1033 \mathrm{~W} ;-8^{\circ} 1242 \mathrm{~S}$ e $-37^{\circ} 4036$ $\mathrm{W} ;-16^{\circ} 442 \mathrm{~S}$, além do Norte de Minas Gerais. Ocupa uma área de aproximadamente $69 \%$ do Nordeste. Caracteriza-se por apresentar alto índice de variabilidade climática intrassazonal e interanual, onde os efeitos climáticos sobre os recursos hídricos influenciam na qualidade de vida da população local. (SANTOS, 2011). Assim, o Semiárido brasileiro é caracterizado pelo déficit hídrico, entretanto, não significa falta de água, ao contrário é considerada a região semiárida mais chuvosa do planeta, pois, sua média pluviométrica varia entre $268 \mathrm{~mm}$ a 800 mm anuais em média, com chuvas irregulares no tempo e no espaço. (AB'SABER, 2003).

$\mathrm{O}$ fenômeno da desertificação como círculo vicioso de degradação, tem a erosão como causadora da redução da capacidade de retenção de água pelo solo, diminuindo a biomassa em decorrência da ausência de matéria orgânica no solo. Este torna-se cada vez menos capaz de conter a água em seus poros, a cobertura vegetal faz-se escassa e empobrecida, além disso, a radiação solar intensa desseca ainda mais o solo e a erosão se intensifica, promovendo a aridez. Trata-se de um processo em que a ação antrópica tem papel fundamental, porquanto o acelera, agravando as consequências através de práticas inadequadas de uso dos recursos naturais.

\section{MATERIAL E MÉTODOS}

O Pólo de Jeremoabo localiza-se no semiárido baiano, com condição climática que abrange $70 \%$ do estado da Bahia, enquanto os $30 \%$ restantes compreendem a zona da mata e o oeste baiano, a predominância do clima caracterizado pela escassez e má distribuição de chuvas. A realidade a respeito das características climáticas são determinantes para a situação socioambiental e não devem ser analisadas, como uma situação irreversível. A situação de vulnerabilidade em que se encontram as comunidades locais pode ser minimizada através da implementação de políticas públicas que tenham por objetivo o ordenamento territorial. 
Este compreende os municípios de Antas, Canudos, Chorrochó, Coronel João Sá, Glória, Jeremoabo, Macururé, Novo Triunfo, Paulo Afonso, Pedro Alexandre, Rodelas, Santa Brígida, e Uauá. MAPA 1

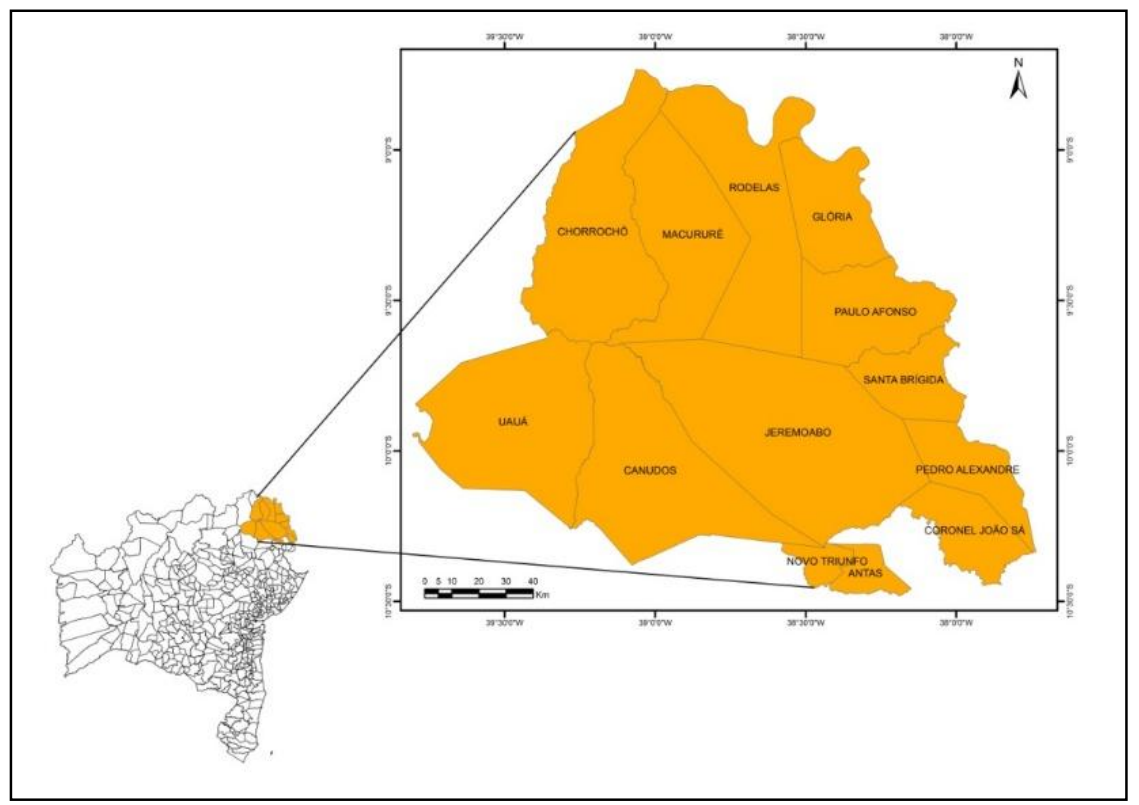

Mapa 1. Localização do Pólo de Jeremoabo no estado da Bahia.

O resumo é resultado da pesquisa de iniciação científica, realizou-se um levantamento bibliográfico, visando a discussão sobre desertificação, semiárido, indicadores socioeconômicos e em seguida organizou-se os dados sociodemográficos em tabelas e gráficos para posteriormente mapear com a utilização do Sistema de Informações Geográficas (SIG). Para a elaboração dos mapas utilizou-se o software Arc View para o processamento de dados vetoriais e introdução dos dados tabulares e o Arc Map. Tal etapa possibilitou ter uma visão ampla da área de estudo, ao relacionar o mapeamento da mesma à da evolução dos números e correlacionar as informações obtidas ao conceito de qualidade de vida em área susceptível a desertificação. As etapas definidas para o desenvolvimento da pesquisa visam contribuir com o estudo dos indicadores socioeconômicos no Pólo de Jeremoabo - BA, possibilitando uma explicação sobre a realidade socioambiental e territorial.

\section{RESULTADOS E/OU DISCUSSÃO}

Os municípios do Pólo de Jeremoabo estão inseridos na região semiárida da Bahia, em meio as relações conflituosas e de poder, onde os interesses geopolíticos prevalecem sobre os interesses socioespaciais. A população total dos municípios, segundo os dados do censo demográfico do Instituto Brasileiro de Geografia e Estatísticas (IBGE-2010), corresponde a aproximadamente 309 mil habitantes. A população rural registra cerca de 130 mil habitantes, representando $43 \%$ da população total, enquanto a população urbana representa $57 \%$, somando mais de 174 mil habitantes.

A tabela 1 expõe os dados sobre a Extração Silvícola dos municípios que integram o Pólo de Jeremoabo em toneladas produzidas, obtidas através do Censo Demográfico do Instituto Brasileiro de Geografia e Estatística (IBGE) entre 1998 e 2014.

A leitura da evolução dos dados acerca da produção silvícola do Pólo de Jeremoabo permite avaliar o desempenho do setor na economia da região. De maneira geral, houve um declínio da produção de todos os frutos na década analisada, a castanha de caju é o principal 
produto extraído no Pólo, registrou um declínio de $70 \%$ de sua produtividade, o umbu teve um declínio de $75 \%$ da produção, o Licuri cerca de $44 \%$, e o angico com $80 \%$.

Tabela 1 - Pólo de Jeremoabo: Extração Silvícola em toneladas entre

1998 e 2014

\begin{tabular}{l|c|c|c|c|c|c|c|c|c}
\hline PRODUÇÃO (T) & $\mathbf{1 9 9 8}$ & $\mathbf{2 0 0 0}$ & $\mathbf{2 0 0 2}$ & $\mathbf{2 0 0 4}$ & $\mathbf{2 0 0 6}$ & $\mathbf{2 0 0 8}$ & $\mathbf{2 0 1 0}$ & $\mathbf{2 0 1 2}$ & $\mathbf{2 0 1 4}$ \\
\hline Castanha de Caju & 98 & 789 & 663 & 219 & 287 & 297 & 321 & 180 & 232 \\
Umbu (fruto) & 585 & 212 & 426 & 247 & 455 & 435 & 446 & 198 & 161 \\
Licuri (coquilho) & 20 & 13 & 39 & 38 & 29 & 23 & 24 & 24 & 22 \\
Angico (casca) & 15 & 8 & 6 & 5 & 5 & 3 & 3 & 3 & 3 \\
\hline
\end{tabular}

Fonte: IBGE (1998- 2014).

A queda da produtividade implica nas condições de vida da população do município, sobretudo, da população do espaço rural que tem como fonte de renda as atividades agropastoris, enfrenta a problemática socioambiental da desertificação, além de carecer de uma política de planejamento que minimize os efeitos do fenômeno e viabilize a produção silvícola na região.

O Índice de Desenvolvimento Econômico (IDE) e o Índice de Desenvolvimento Social (IDS) destinam-se a caracterizar, por meio quantitativo, os diferentes níveis de desenvolvimento dos municípios do Pólo de Jeremoabo. O estudo da evolução desses índices apresenta-se como um recurso na elaboração de políticas públicas que objetivem melhorar as condições sociais e econômicas dos municípios, contribuindo para atenuar as desigualdades.

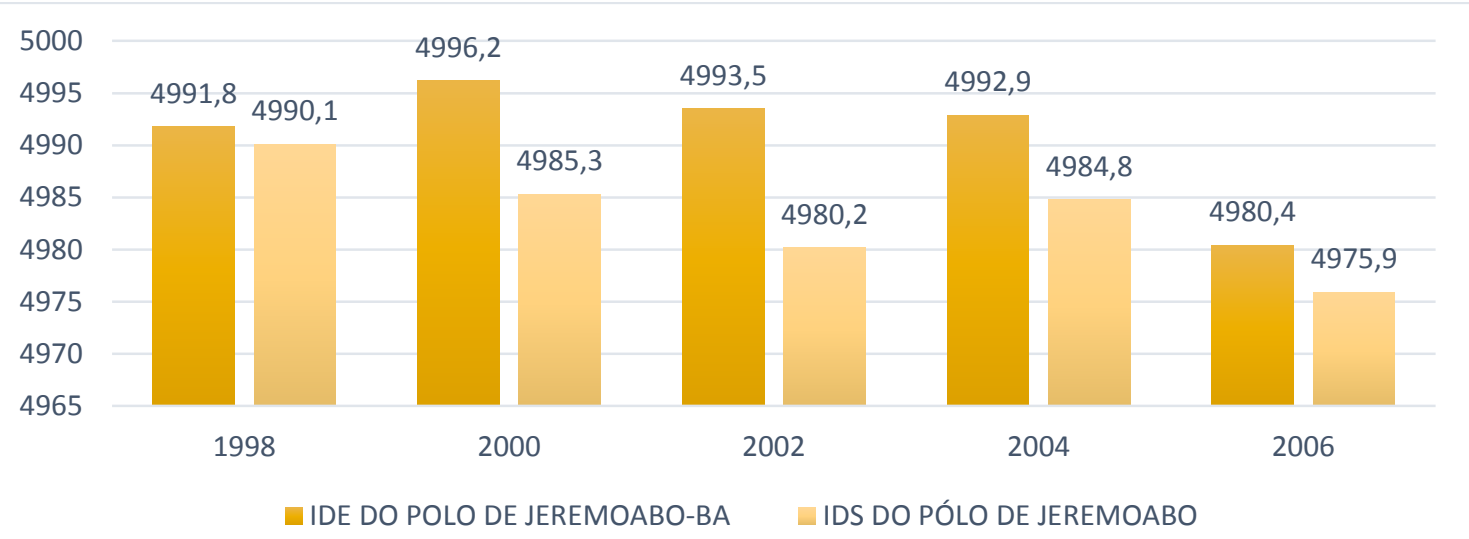

Gráfico 1. Índice de Desenvolvimento Econômico e índice de Desenvolvimento Social do Pólo de Jeremoabo.

Os valores do Índice de Desenvolvimento Econômico com dados referentes ao ano de 1998 não apresentam grandes alterações em relação ao IDE do ano de 2006. Paulo Afonso é o município com o desempenho mais importante quanto ao IDE do Pólo de Jeremoabo entre 1998 a 2006, porém na análise da evolução do índice percebe-se que houve um crescimento de cerca de $2 \%$ no ano de 2000, declinando nos anos de 2002 e 2004 . No ano de 2006 o índice do município apresentou uma melhora mas não muito significativa. O município de Novo Triunfo é o que apresenta os menores valores no Índice de Desenvolvimento Econômico do Pólo de Jeremoabo, o ano de 2006 foi o de pior desempenho do IDE onde o mesmo apresentou um declínio de $0,8 \%$ entre 1998 a 2006.

Os dados demonstram, que os municípios com IDE mais elevado são aqueles que possuem atividades industriais ou agricultura comercial mais desenvolvida. Municípios com pecuária extensiva e agricultura familiar não integrada a complexos agroindustriais, tendem a apresentar um valor menor de IDE. A leitura dos índices, permite afirmar que os valores do IDS 
são superiores aos do IDE, permitindo afirmar que a questão social está diretamente vinculada à econômica. Municípios com o menor número populacional, possuindo apenas uma indústria representativa, gera renda significativa, porém esta não é apropriada pela população local, no entanto este fator contribui para mascarar os dados.

Isto ocorre por falta de continuidade da Política Nacional de Assistência Social (PNAS/2004) que demonstrara a intenção de construir coletivamente o redesenho desta política, na perspectiva da criação do Sistema Único de Assistência Social (SUAS). Esta iniciativa, decididamente, traduz o cumprimento das deliberações da IV Conferência Nacional de Assistência Social, realizada em Brasília, em dezembro de 2003, e denota o compromisso do Ministério do Desenvolvimento Social e Combate à Fome (MDS/SNAS), e do Conselho Nacional de Assistência Social em materializar as diretrizes da Lei Orgânica da Assistência Social (LOAS).

Analisando os Indicadores Socioeconômicos percebe-se que o IDS e o IDE teve um declínio de 1,5\% entre 1998 a 2006, em termos geral o Índice de Desenvolvimento Econômico é cerca de $8 \%$ maior que o Índice de Desenvolvimento Social. A Produção Silvícola também apresentou declínio na produtividade, aspecto considerado significativo, visto que as atividades agropastoris caracterizam-se como a atividade mais expressivo para o sustento dos habitantes. Esse cenário reflete as consequências do processo de desertificação, que interfere na produção agrícola, reforçando a necessidade de políticas públicas para a melhoria da qualidade de vida de seus habitantes.

\section{CONSIDERAÇÕES FINAIS}

Observando os números referentes aos Indicadores Socioeconômicos percebe-se que o IDS e o IDE teve um declínio de 1,5\% entre 1998 a 2006, em termos geral o Índice de Desenvolvimento Econômico é cerca de $8 \%$ maior que o Índice de Desenvolvimento Social. A Produção Silvícola também apresentou declínio na produtividade, aspecto considerado significativo, visto que as atividades agropastoris caracterizam-se como a atividade mais expressiva para o sustento dos habitantes. O cenário reflete as consequências do processo de desertificação, que interfere na produção agrícola, reforçando a necessidade de políticas públicas de ordenamento territorial para a melhoria da qualidade de vida de seus habitantes.

O texto da Carta Européia do Ordenamento do Território (1983) expõe que ordenar o território é garantir que cada uma das suas parcelas seja dada a utilização mais conforme a respectiva vocação, compatibilizando o desenvolvimento socioeconômico equilibrado das regiões, com a gestão responsável dos recursos naturais, e utilização racional dos solos. Dessa forma, as múltiplas dimensões de análise do ordenamento territorial irão possibilitar uma análise das especificidades e generalidades do Pólo de Jeremoabo, identificando as principais necessidades da população. Nessa perspectiva, o ordenamento territorial conta com o planejamento, uma importante ferramenta que irá orientar políticas públicas mais adequadas ao desenvolvimento territorial e a realidade local, buscando o desenvolvimento socioeconômico da região semiárida.

\section{REFERÊNCIAS}

AB'SÁBER, A. Os domínios de natureza no Brasil: potencialidades paisagísticas. São Paulo: Ateliê Editorial, 2003.

CEOT/CEMAT. “A Regional/Spatial Charter for Europe”. Estrasburgo: Conselho de França. 1983.

IBGE. Instituto Brasileiro de Geografia e Estatísticas. Censo Demográfico. 2010. 